\title{
Oil Produced Water Treatment Using Advanced Oxidative Processes: Heterogeneous-Photocatalysis And Photo-Fenton
}

\section{Priscila Christopoulos Silva ${ }^{1}$, Nathália Pereira Ferraz ${ }^{1}$, Elen Aquino Perpetuo ${ }^{1}$ And Yvan Jesús Olortiga AsENCIOS ${ }^{1 *}$}

1 Universidade Federal de São Paulo, Instituto do Mar, Campus Baixada Santista, São Paulo, Brazil

*CORRESPONDING AUTHOR, yvan.jesus@unifesp.br

Received on 30 August 2018

Received in revised form on 20 March 2019

Accepted on 22 March2019

Editor: Wânia Duleba, Universidade de São Paulo, Bražil
Citation:

Christopoulos Silva, P., Ferraz, N.P., Perpetuo, E.A., Asencios, Y.J.O., 2019. Oil Produced Water treatment using Advanced Oxidative Processes: Heterogeneous-Photocatalysis and PhotoFenton. Journal of Sedimentary Environments, 4 (1): 99- 107.

\section{Abstract}

The Oil Produced Water (OPW) is an effluent produced during the oil extraction process. Owing to its complex composition and toxicity it must be treated by wastewater treatment technologies. However, traditional facilities may be unable to remove all the anthropogenic or naturally occurring compounds. This can result in their discharge to surface water and ultimately affecting the sedimentary environment. The present work shows the application of two Advanced Oxidative Processes (AOPs), Photocatalysis and Photo-Fenton to treat two kinds of effluents: phenolic solution made in seawater, and a real sample of OPW from Rio Grande do Norte, Brazil. Two commercial catalysts were used: $\mathrm{TiO}_{2}$ (for Heterogeneous-Photocatalysis process), and $\mathrm{FeSO}_{4} .7 \mathrm{H}_{2} \mathrm{O}$ (for Photo-Fenton process). The catalysts were characterized by X-Ray Diffraction Analysis (XRD), and Diffusive Reflectance Spectroscopy (DRS). In the two AOPs the following parameters were evaluated: initial $\mathrm{pH}$ of effluent (acid, neutral and alkaline), presence of $\mathrm{H}_{2} \mathrm{O}_{2}$ $(0.3 \% \mathrm{v} / \mathrm{v})$ and time under ultra-violet (UV) irradiation

\section{Introduction}

During the extraction of oil in offshore operations, the water that reaches the surface is called: Oil Produced Water (OPW), defined as a mixture of water, salts, suspended solids, organic compounds, heavy metals, microorganisms and dispersed oil droplets (Judd et al., 2014; Cheriyan and Rajagopalan, 1998). The organic compounds present in OPW include: benzene, toluene, ethylbenzene, xylene, naphthalene, phenanthrene, dibenzothiophene, polyaromatic hydrocarbons (HPA), phenols, gases and heavy metals (Judd et al., 2014; Neff, 2002). Present in the OPW are also ions, such as $\mathrm{Na}^{+}$, $\mathrm{K}^{+}, \mathrm{Mg}^{2+}, \mathrm{Ca}^{2+}, \mathrm{Cl}^{-}, \mathrm{SO}^{-2}, \mathrm{HCO}_{3}{ }^{-1}$ and some heavy metals, such as $\mathrm{Cd}, \mathrm{Mn}, \mathrm{Hg}, \mathrm{Zn}, \mathrm{Fe}, \mathrm{Cr}$ and $\mathrm{Cu}$; furthermore, metals (254nm); aiming to find the suitable conditions for OPW treatment. The results showed an efficiency of $99 \%$ for phenol removal, despite the high content of salts present in seawater. In the treatment of the two effluents by the AOPs, the reaction reached chemical equilibrium in $1 \mathrm{~h}$ under UV irradiation $(254 \mathrm{~nm})$; the best $\mathrm{pH}$ to treat the effluents was $\mathrm{pH} 7$, in the presence of $\mathrm{H}_{2} \mathrm{O}_{2}(0.3 \% \mathrm{v} / \mathrm{v})$ and by increasing temperature to $75^{\circ} \mathrm{C}$ (in the case of the real sample of OPW). The results of this work show that the two studied AOPs can be used in the oil industry, for OPW treatment and to treat effluents (with high salinity) contaminated with phenol, to remove organic compounds in order to reduce their toxicity, and consequently assist towards a better quality of the sedimentary environment. The best results were obtained by the Photo-Fenton process.

Keywords: Contaminants. Treatment. Oil Produced Water. Seawater. Phenol. Advanced Oxidative Processes (AOPs).

have a variable composition, but often, barium and iron are the major elements (Ray and Engelhardt, 1992).

The oil contained in the OPW can be classified into three fractions: dispersed oil, oil-in-water or water-in-oil emulsions, and dissolved organic compounds (Liu et al., 2016). The first two can be removed by gravity or hydrocyclone (after demulsifier addition), but the residual oil droplets and dissolved organic compounds (including aromatic compounds and polycyclic aromatic hydrocarbons) remain unchanged.

The occurrence of aromatics is of great concern because of their high resistance to biodegradation, toxicity to marine biota, and possible carcinogenicity and mutagenicity (Jing et al., 2014). The treatment of OPW is necessary due to the large volumes 
that are generated during the production of crude oil and, especially, due to the impacts that it causes to the environment when it is improperly discarded. These impacts, include biological effects on marine pelagic ecosystems, causing: endocrine, non-endocrine and reproductive problems (Bakke et al., 2013). In Brazil, according to the Exploration and Production Database (of the National Agency of Petroleum), the average OPW production in 2017 was around 3.7 million $\mathrm{bbl} /$ day and oil production was approximately 2.4 million $\mathrm{bbl} /$ day, considering the Brazilian onshore and offshore production. In Brazil, the Resolution, $\mathrm{n}^{\circ} 393 / 2007$ of the National Environmental Council (CONAMA) establishes that the monthly average limit of Total Oils and Greases (TOG) in OPW (for discard) is $29 \mathrm{mg} . \mathrm{L}^{-1}$.

Numerous OPW treatment technologies have been developed (including hydrocyclone, filtration, adsorption and osmosis) that allow for injection, discharge to the land surface (if managed correctly), or beneficial reuse (Ahmadun et al., 2009; Carvalho, 2016). However, traditional facilities may be unable to remove all the contaminants contained in OPW. This can result in their discharge to surface water and ultimately affecting the sedimentary environment.

Advanced Oxidative Processes (AOPs) are used for the degradation of contaminants in water. In HeterogeneousPhotocatalysis (an AOP), a semiconductor, for example: $\mathrm{TiO}_{2}$, is activated by UV or visible radiation. The semiconductor is characterized by conduction bands (CB) and valence bands (VB), the energetic region between bands is known as bandgap energy $\left(E_{b t}\right)$. The absorption of photons with energy $(\mathrm{E}=\mathrm{h} . v$, where $\mathrm{h}$ is the Planck's constant and $v$ is the photon's frequency) greater than $\mathrm{E}_{\mathrm{bt}}$, promotes an electron from the valence band to the conduction band $\left(\mathrm{e}^{-}\right)$generating an electron-hole in the valence band $\left(\mathrm{h}^{-}\right.$; Ibhadon and Fitzpatrick, 2013) (Equation 1):

$$
\text { Semiconductor }+ \text { h. } v\left(>E_{b g}\right) \rightarrow e_{C B}^{-}+h_{V B}^{-}(1)
$$

However, if electrons $\left(e_{C B}^{-}\right)$and electron-holes $\left(h_{V B}^{-}\right)$ migrate to the surface of the semiconductor without recombination, they can participate in several oxidation reactions. In the oxidation of organic compounds in water the electron-holes $\left(h_{V B}^{-}\right)$present on the surface of the semiconductor induce the oxidative decomposition of adsorbed organic molecules. These electron-holes can also react with water molecules (and also with the - $\mathrm{OH}$ ions present in the water) to produce the hydroxyl $\operatorname{radical}(\bullet \mathrm{OH})$. This $\bullet \mathrm{OH}$, quickly attacks organic pollutants in the solution leading to mineralization $\left(\mathrm{CO}_{2}\right.$ and $\left.\mathrm{H}_{2} \mathrm{O}\right)$ (Nogueira and Jardim, 1998).

A simple search in the Scopus database, using the keywords: "seawater", "photocatalysis", reported that between 1997 and 2018, only 60 scientific papers on this subject were produced worldwide. The number of papers is even smaller when the search is restricted to the keywords: seawater, photocatalysis and phenol. The same occurs with the terms: photocatalysis, catalysis, Oil Produced Water
(OPW). Thus, it is possible to affirm that applications of photocatalysis to the degradation of organic compounds in seawater and in OPW, are topics not well studied, yet.

In this context, considering that depollution of water leads to a better quality of the sedimentary environment; the aim of this study was to investigate the degradation of organic compounds in OPW using two AOPs: HeterogeneousPhotocatalyst and Photo-Fenton. Two effluents were used for this study. The first effluent was a phenolic solution made in seawater, in order to simulate an OPW. Phenol was used as a model molecule representing the aromatic fraction of crude oil (aromatic alcohols are highly soluble in water). The use of seawater is justified by considering that the high content of salts is similar to that present in OPW, and, moreover at longer reservoir lifetimes, seawater may predominate the composition of OPW since it is used as fluid of injection into the reservoir (Ray and Engelhardt, 1992; Jing et al., 2014). The other effluent analyzed in this study was a real sample of OPW collected from an oil company located in Rio Grande do Norte, Brazil. For the two AOPs two commercial catalysts were used: $\mathrm{TiO}_{2}$ and $\mathrm{FeSO}_{4} \cdot 7 \mathrm{H}_{2} \mathrm{O}$. The initial $\mathrm{pH}$ of effluents and irradiation time under UV light were varied in order to identify the best conditions for the OPW treatment by AOPs.

\section{Materials and Methods}

\subsection{Catalysts}

Two commercial catalysts were used: $\mathrm{TiO}_{2}$ (Synth 99,99\% P.A.) for the Heterogeneous-Photocatalysis and $\mathrm{FeSO}_{4} .7 \mathrm{H}_{2} \mathrm{O}$ for the Photo-Fenton. Both were characterized by X-Ray Diffraction (XRD) in a Rigaku miniflex diffractometer $(30 \mathrm{Kv}-10 \mathrm{~mA})$ with scanning from $5^{\circ}$ to $80^{\circ}$. The crystalline structures were identified considering the International Center of Diffraction Database (ICDD). The average crystallite sizes were determined from XRD linebroadening measurements using the Scherrer Equation (Jenkins and Snyder, 1996): $d=\mathrm{k} \cdot \lambda /\left(\beta_{\mathrm{hkl}} \cdot \cos \theta\right)$, where $d$ is the average crystallite size, $\mathrm{k}$ is the shape factor, taken as $0.89, \lambda$ is the wavelength of $\mathrm{CuK} \alpha$ radiation, $\beta_{\mathrm{hkl}}$ is the full width at half maximum (FWHM) of the particular peak and $\theta$ is the Bragg's angle.

The catalysts were also characterized by diffuse reflectance spectroscopy (DRS) in a Cary 5E Spectrometer (200 to $800 \mathrm{~nm}$ ). The band-gap energy (eV) of the catalyst was provided by the steep linear extrapolation part from the absorption profile obtained in DRS, as described in the literature (Wood and Tauc, 1972).

\subsection{Effluents}

The effluents were identified as the following:

- Phenol in seawater: a stock solution of phenol (46 mg. $\left.\mathrm{l}^{-1}\right)$ was 
prepared using seawater as solvent; the fresh seawater was collected from a clean and preserved region of the beach in Guarujá city (São Paulo State, Brazil) and passed through a filter membrane (cellulose) of 0.22 $\mu \mathrm{m}$.

- Oil Produced Water (OPW): a real sample of OPW obtained from an oil company located in Rio Grande do Norte, Brazil. This effluent was degassed and passed through a filter membrane (cellulose) of $0.22 \mu \mathrm{m}$.

\subsection{Photocatalytic tests}

In the Heterogeneous-Photocatalysis process: $\mathrm{TiO}_{2}$ was used in a ratio of $1 \mathrm{~g}_{\text {catalysts }}$. $\mathrm{L}_{\text {effluent }}{ }^{-1}$ and $\mathrm{H}_{2} \mathrm{O}_{2}(0.3 \% \mathrm{v} / \mathrm{v})$. In the case of the Photo-Fenton process, $4.2 \mathrm{mg}$ of $\mathrm{FeSO}_{4} .7 \mathrm{H}_{2} \mathrm{O}$ and $\mathrm{H}_{2} \mathrm{O}_{2}$ in a molar ratio of 1:10 (catalyst: $\mathrm{H}_{2} \mathrm{O}_{2}$ ) were used.

In both processes, $25 \mathrm{~mL}$ of effluent was used, and the initial $\mathrm{pH}$ was varied as: 3,7 and 10 , with addition of $\mathrm{H}_{2} \mathrm{SO}_{4}$ $(0.1 \mathrm{M})$ or $\mathrm{NaOH}(0.1 \mathrm{M})$. A glass beaker $(500 \mathrm{ml})$ was used as a batch reactor, which was open to ambient air, the reactor was under magnetic stirring. The reactor was confined in a dark chamber with internal ventilation and exhaust. The irradiation for each process was provided by six UV lamps (253.7 nm, 15watt, 220 volt) and the illumination to the reactor was from the top. The catalyst/effluent separation was done by centrifugation $(12,000 \mathrm{rpm})$.

The phenol concentration was monitored during each photocatalytic reaction by spectrophotometry through the colorimetric method with 4-aminoantipyrine (APHA Method D 5530 and EPA Method 604), and a calibration curve at $\lambda=510 \mathrm{~nm}$. The colorimetric method was used previously by other researchers (Xu et al., 2015; Sun et al., 2016; Zhu et al., 2016), for studies of photocatalytic degradation of phenol. Some tests were also monitored by High Performance Liquid Chromatography (HPLC, Shimadzu i-series Chromatograph) with furnace temperature of $35^{\circ} \mathrm{C}$, the mobile phase consisted of aqueous acetonitrile solution with a flow of $0.8 \mathrm{~mL}$.minute ${ }^{-1}$, and a C-18 column $(5 \mu \mathrm{m}, 4.6 \times 250 \mathrm{~mm})$ in a reverse mode. In this process the phenol removal percent $\left(\mathrm{X}^{\%} \%\right)$ was calculated as: $\left.\mathrm{X} \%=\left(\mathrm{M}_{\mathrm{i}}-\mathrm{M}_{\mathrm{f}}\right) / \mathrm{M}_{\mathrm{i}}\right)$ x 100 , where $\mathrm{M}_{\mathrm{i}}$ and $\mathrm{M}_{\mathrm{f}}$ are the phenol concentrations at the beginning and at the end of each experiment, respectively.

In the case of the photocatalytic tests using OPW, the organic matter present in this sample was characterized by UV/Vis Spectrophotometer (Global Trade Technology, model: UV-5100) in scan mode, as described by Albrektienè et al. (2012) and Claro (2013).

\section{Results and Discussion}

\subsection{Characterization of catalysts by X-Ray Diffraction (XRD)}

The results of the photocatalysts obtained by XRD analysis are shown in Fig. 1a-b. From this analysis and from the JCPDS database, it was possible to identify that the
$\mathrm{FeSO}_{4} .7 \mathrm{H}_{2} \mathrm{O}$ photocatalyst (Fig. 1b) is present as a single monoclinic phase (PDF 25-0409), with unit cell parameters: $\mathrm{a}=7.624 \AA, \mathrm{b}=7.648 \AA$ and $\mathrm{c}=7.123 \AA$. Additionally, the average crystallite size calculated by the Scherrer equation (Jenkins and Snyder, 1996) was $23 \mathrm{~nm}$. According to the Diffuse Reflectance Spectroscopy (DRS) analysis, the bandgap energy of $\mathrm{FeSO}_{4} .7 \mathrm{H}_{2} \mathrm{O}$ photocatalyst was $1.98 \mathrm{eV}$.

The XRD pattern of the $\mathrm{TiO}_{2}$ photocatalyst (Fig. 1a) shows the single anatase phase (tetrahedral) (PDF 21-1272) with a Bragg angle and unit cell parameters of the tetrahedral phase of $\mathrm{a}=3.73 \AA, \mathrm{b}=0$ and, $\mathrm{c}=9.37 \AA$. The average crystallite size of $\mathrm{TiO}_{2}$ calculated by the Scherrer equation (Jenkins and Snyder, 1996) was $38 \mathrm{~nm}$; and according to Diffuse Reflectance Spectroscopy (DRS) the Band-gap Energy of $\mathrm{TiO}_{2}$ was $3.2 \mathrm{eV}$. It is known that the anatase phase of $\mathrm{TiO}_{2}$ presents good photocatalytic activity under UV light, better than the rutile phase. This is due to the fact that $\mathrm{TiO}_{2}$ has low recombination rate of "photogenerated-holes and electrons" (Carp et al., 2004); this property is very important for heterogeneous photocatalysis.

\subsection{Photocatalytic test: Phenol in seawater}

\subsubsection{Heterogeneous-Photocatalysis Test $\left(\mathrm{TiO}_{2}\right)$}

Firstly, the photocatalytic tests were carried out over $\mathrm{TiO}_{2}$ in the absence of $\mathrm{H}_{2} \mathrm{O}_{2}$. The initial $\mathrm{pH}$ was regulated to: 3,7 and 10 . The results are shown on the chromatogram profile (by HPLC analysis), in Fig. 2a-d. According to the result shown in Fig. 2a, the profile of the initial phenol solution presents two peaks, the first was assigned to salts present in seawater, and the second to phenol (46 mg.L $\left.{ }^{-1}\right)$. The profile obtained for the sample after the photocatalysis at $\mathrm{pH} 3$ (Fig. $2 \mathrm{~b})$, reported a final concentration of $31 \mathrm{mg} \cdot \mathrm{L}^{-1}$ meaning that the $33 \%$ of phenol was removed from seawater.

Nevertheless, the results at pH 7 (Fig. 2c) and 10 (Fig. 2d) reached lower removal percentage values $(11 \%$ and $7 \%$, respectively) demonstrating that the $\mathrm{pH}$ of the initial solution influenced the removal of phenol. Similar results were reported by Seftel et al. (2014) and Moraes (2003) for the photocatalysis of phenol in distilled water. Our finding means that even in the presence of high seawater salinity, the low $\mathrm{pH}$ promotes high phenol removal rates. According to the chromatograph profiles of Figs. $2 \mathrm{~b}-\mathrm{d}$, there were no other intermediates formed after phenol degradation (not detectable under chromatograph detection limit).

The chromatographs for samples after 1 hour of Heterogeneous-Photocatalysis using $\mathrm{TiO}_{2}$ with addition of $\mathrm{H}_{2} \mathrm{O}_{2}$ $(0.3 \% \mathrm{v} / \mathrm{v})$ under UV are shown in Fig. 3a-c. In Fig. 3a-b, the peaks of phenol after the photocatalysis at $\mathrm{pH} 3$ and 7 correspond to 5.9 mg.L $\mathrm{L}^{-1}$ and $2.9 \mathrm{mg} . \mathrm{L}^{-1}$, which result in the phenol removal of $87 \%$ and $94 \%$, respectively.

The photocatalysis at $\mathrm{pH} 10$ (Fig. 3c) resulted in $71 \%$ of phenol removal. The excess $\mathrm{H}_{2} \mathrm{O}_{2}$ appears in the chromatograph, however, the peak of $\mathrm{H}_{2} \mathrm{O}_{2}$ is less intense at $\mathrm{pH} 10$ which is reasonable, since $\mathrm{H}_{2} \mathrm{O}_{2}$ is less stable at basic $\mathrm{pH}$. 

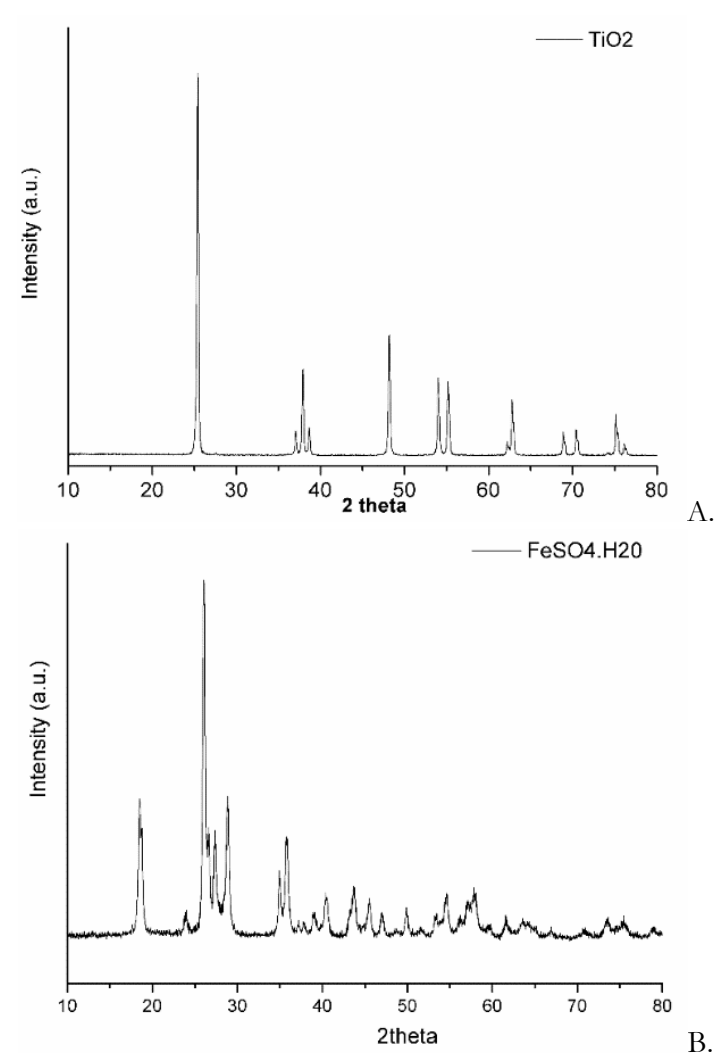

Fig. 1. XRD diffraction patterns of photocatalysts: $\mathrm{A}$. $\mathrm{TiO}_{2}$ and; $\mathrm{B}$. $\mathrm{FeSO}_{4} \cdot 7 \mathrm{H}_{2} \mathrm{O}$.

The $\mathrm{pH}$ of the phenolic solutions after photocatalysis were also measured (final $\mathrm{pH}$ ). There was a slight increase after the photocatalysis in $\mathrm{pH} 3$ and 7 samples and a significant reduction for the $\mathrm{pH} 10$ sample, reaching $\mathrm{pH}$ 8.5.

The increase in the final $\mathrm{pH}$ of the samples at 3 and 7 (to 4 and 8 , respectively), can be explained by the formation of organic compounds such as short-chain organic acids, as a product of phenol degradation process. Probably these organics are in very low concentration since they were not seen by chromatography, and are in ionic form (example: acetate ions) and in equilibrium in water.

The formation of these ions leads to a $\mathrm{pH}$ increase (due to the $\mathrm{H}+$ protons suppressed from water) to maintain the equilibrium (established by the Le Chatelier Principle; Atkins and Jones, 2010). The results indicated that the Heterogeneous-Photocatalysis under UV with $\mathrm{TiO}_{2}$ photocatalyst plus $\mathrm{H}_{2} \mathrm{O}_{2}$ reached the highest removal values of phenol at $\mathrm{pH} 3$ and $\mathrm{pH} 7$.

The kinetic results for the heterogeneous-photocatalysts with $\mathrm{TiO}_{2}$ plus $\mathrm{H}_{2} \mathrm{O}_{2}$ under UV light $(254 \mathrm{~nm})$ are shown in Fig.4. According to these results, at $\mathrm{pH} 3$ and 7 the process kinetics are very fast, and, the most favorable result was at $\mathrm{pH}$ 7 (94\% degradation). The reaction reaches the equilibrium after 1 hour of exposure to UV light.
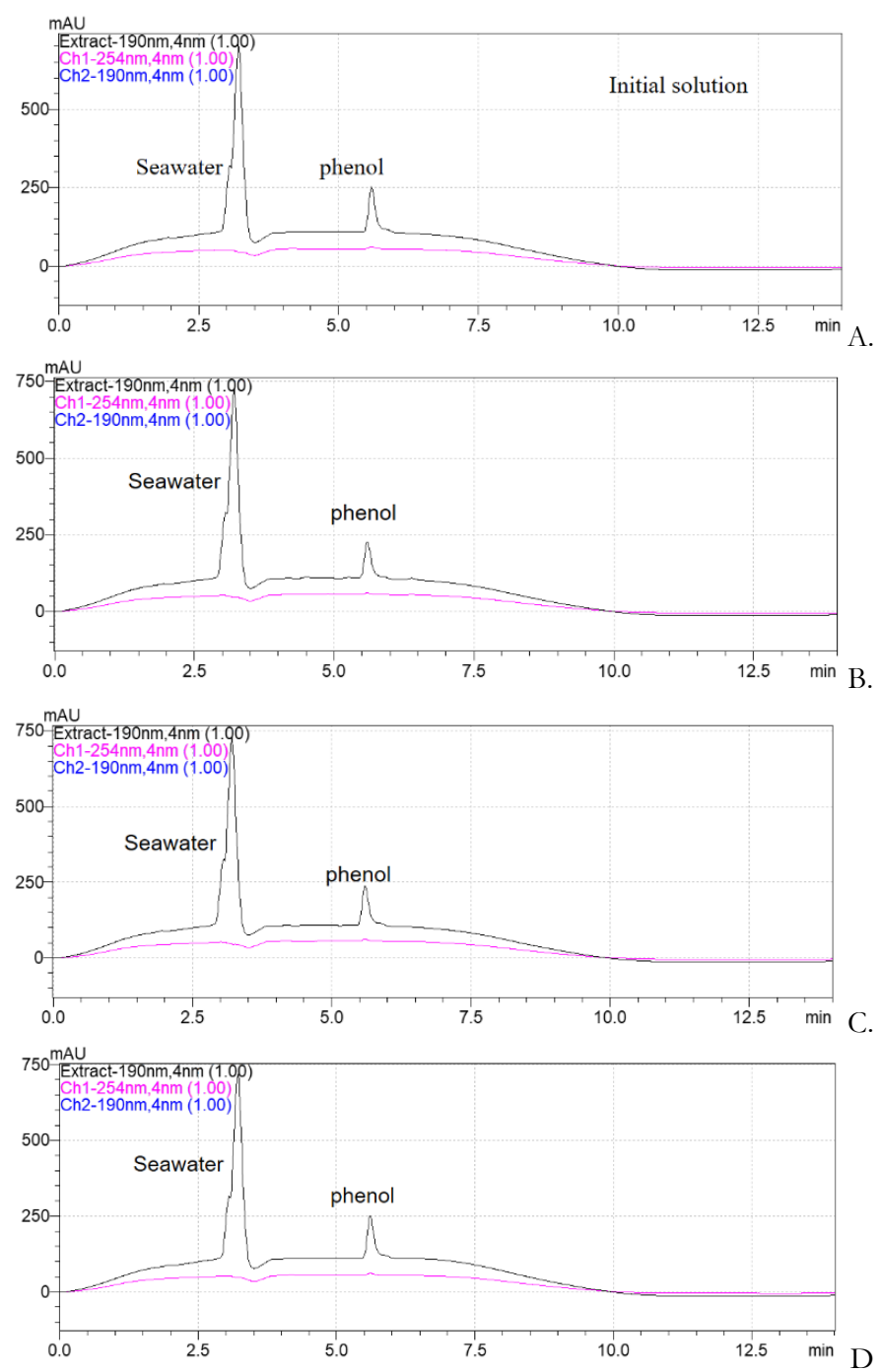

Fig. 2. Chromatograms of Heterogeneous-Photocatalysis tests using UV light (254nm) for 1 hour, without $\mathrm{H}_{2} \mathrm{O}_{2}$. A. initial solution of phenol in seawater (46 mg.. ${ }^{-1}$ ), before photocatalysis; B. sample after photocatalysis at $\mathrm{pH} 3$; C. sample after photocatalysis at $\mathrm{pH}$ 7; D. samples after photocatalysis at $\mathrm{pH} 10$.

\subsubsection{Photo-Fenton test $\left(\mathrm{FeSO}_{4} .7 \mathrm{H}_{2} \mathrm{O}\right)$}

The phenol removal \% reported in Photo-Fenton process was as high as that of Heterogeneous-photocatalysis. The chromatographs are shown in Fig.5, where the phenol removal reached 99\% (Figs. 5a and 5b).

An almost complete phenol removal was obtained at $\mathrm{pH} 3$. The high efficiency of the process at this solution $\mathrm{pH}$ can be explained by the fact that $\mathrm{Fe}^{3+}$ and $\mathrm{Fe}^{2+}$ are very stable acidic media, which favors the interaction of these ions with $\mathrm{H}_{2} \mathrm{O}_{2}$, generating hydroxyl radicals $(\bullet \mathrm{OH})$ and oxidizing phenolic molecules in water (equations 2 and 3 ):

$$
\begin{aligned}
& \mathrm{Fe}^{2+}+\mathrm{H}_{2} \mathrm{O}_{2} \rightarrow \mathrm{Fe}^{3+}+{ }^{-} \mathrm{OH}+\mathrm{OH}^{2} \\
& \mathrm{Fe}^{3+}+\mathrm{H}_{2} \mathrm{O}_{2}+\mathrm{hv} \rightarrow \mathrm{Fe}^{2+}+\mathrm{H}^{+}+\mathrm{OH}
\end{aligned}
$$



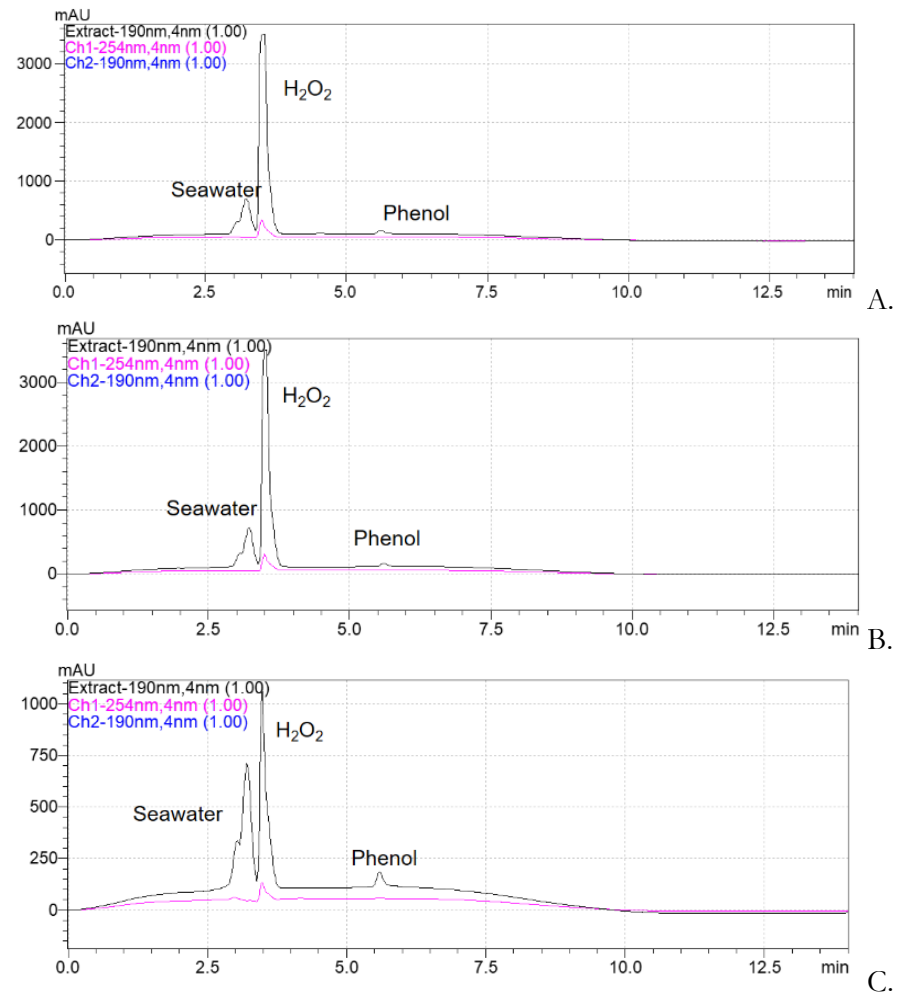

Fig. 3. Chromatograms of Heterogeneous-Photocatalysis tests using UV light $(254 \mathrm{~nm})$ plus $\mathrm{H}_{2} \mathrm{O}_{2}$ oxidizer $(0.3 \% \mathrm{v} / \mathrm{v})$ : A. Photocatalysis at $\mathrm{pH} 3$; B. Photocatalysis at $\mathrm{pH} 7$ and; C. Photocatalysis at $\mathrm{pH} 10$.

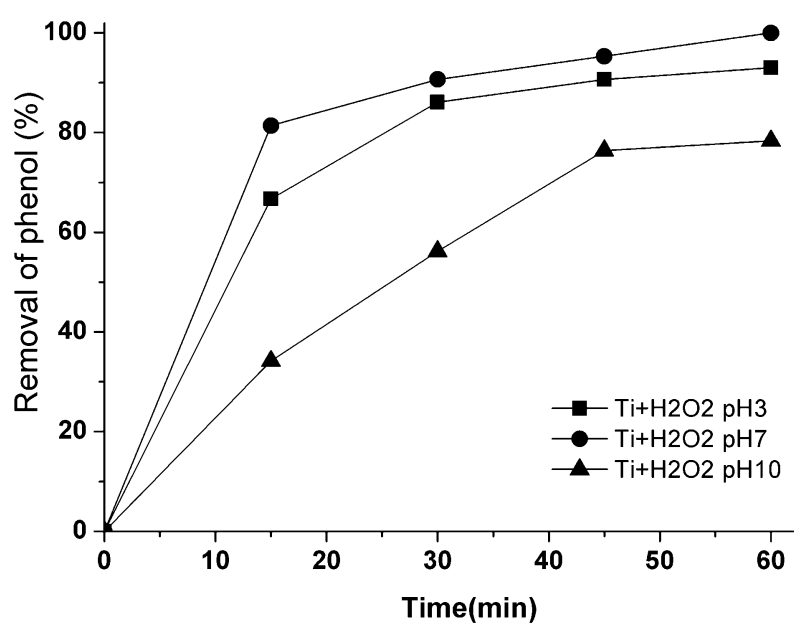

Fig. 4. Kinects of phenolic degradation by heterogeneousphotocatalysis with $\mathrm{H}_{2} \mathrm{O}_{2}(0.3 \% \mathrm{v} / \mathrm{v})$ under UV $(254 \mathrm{~nm})$.

Wang et al. (2014) reported phenol removal of 85\% (in distilled water) for samples with $\mathrm{pH} 3$ when submitted to the Fenton process. In parallel, Kuo (1992) and Kiwi et al. (2000) found that at $\mathrm{pH} \approx 3$ the hydroxyl radicals are the most active species in the degradation of organic compounds in PhotoFenton process. Similar results were found when the PhotoFenton was carried out at $\mathrm{pH} 7$.

Similarly, for the heterogeneous-photocatalysis, the PhotoFenton process was less effective at $\mathrm{pH} 10$ and the peak of phenol present in Fig. 5c corresponds to the concentration of
8.2 mg.L-1, which result in 57\% phenol removal. This can be related to the low stability of $\mathrm{H}_{2} \mathrm{O}_{2}$ in basic media, which hinders the interaction with $\mathrm{Fe}^{2+}$ and $\mathrm{Fe}^{3+}$, and therefore leads to a less effective oxidation process.
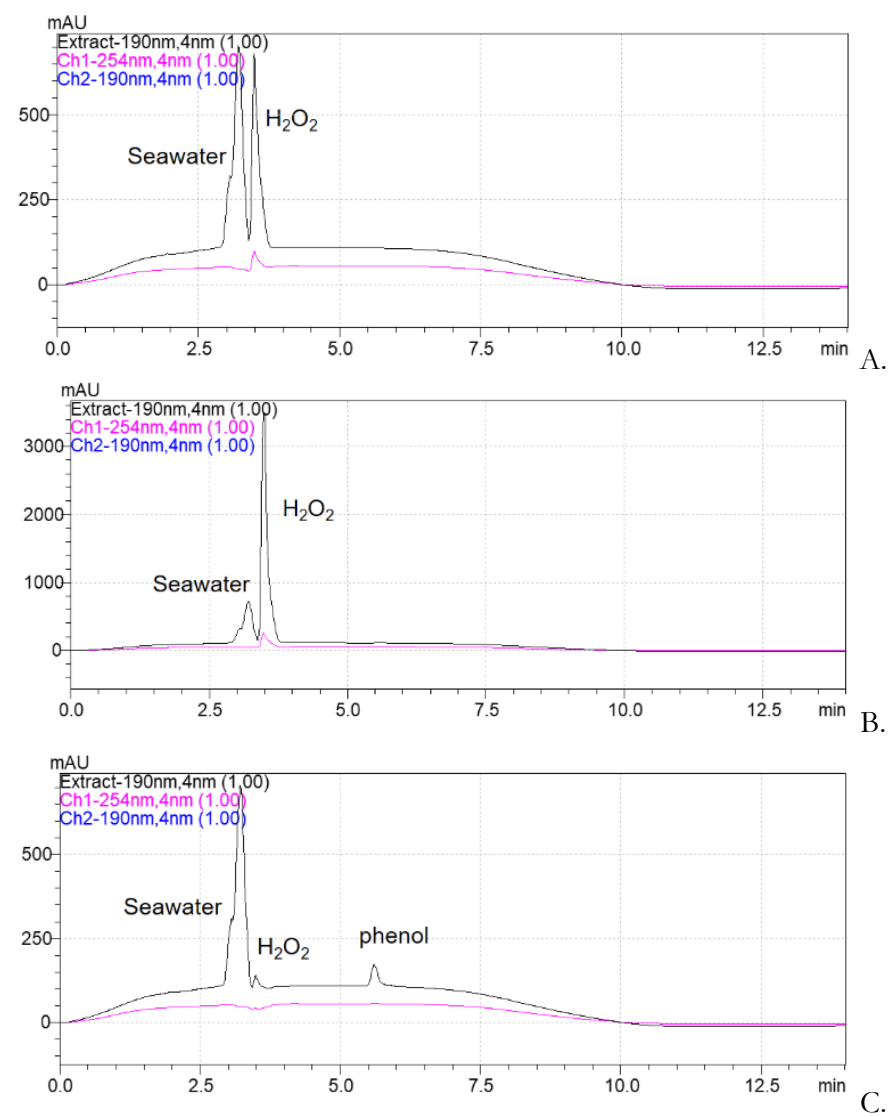

Fig. 5. Chromatograms of Photo-Fenton test using UV light (254nm). A. Photo-Fenton at $\mathrm{pH} 3$; B. Photo-Fenton at pH 7; C. Photo-Fenton at pH 10.

The kinetic results in Photo-Fenton reaction are shown in Fig. 6. According to the profiles, as expected, the reaction was very fast at low $\mathrm{pH}$ (3 and 7), and was less efficient and slower at $\mathrm{pH} 10$. The kinetic test showed that the reaction reached the equilibrium after 1 hour of irradiation. The results were similar to those found in Heterogeneous-Photocatalysis experiments, and seem to indicate that the $\mathrm{pH}$ of the solution influences the reactivity of $\mathrm{H}_{2} \mathrm{O}_{2}$ and the stability of the phenolic species in aqueous media at different $\mathrm{pH}$.

Figure 7 presents the comparison of different AOPs studied in this work, for the degradation of phenol in seawater. That figure also presents the adsorption of phenol over the catalysts in the dark, which clearly shows that there was no significant contribution of the adsorption of the phenol by the $\mathrm{TiO}_{2}$ surface. UV radiation $(254 \mathrm{~nm})$ and $\mathrm{UV}+\mathrm{H}_{2} \mathrm{O}_{2}(0.3 \%)$ removed significantly phenol. Nevertheless, in all case, the Heterogeneous-Photocatalysis and Photo-Fenton process reached the highest value, showing that even in the presence of high seawater salinity, the photocatalytic process is effective.

The results observed before, indicated that the AOP is 
effective even in the presence of water with high salinity. As is known, the presence of salts is interfering factors in reducing the efficiency of AOPs, especially due to higher $\mathrm{NaCl}$ contribution, which releases chloride ions $\left(\mathrm{Cl}^{-}\right)$that compete for hydroxyl radicals.

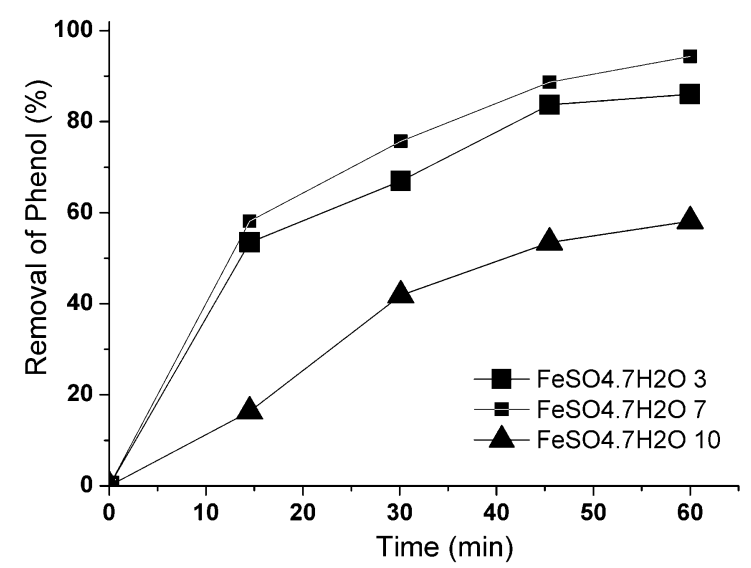

Fig. 6. Kinects study of Photo-Fenton reactions at different initial solution $\mathrm{pH}$.

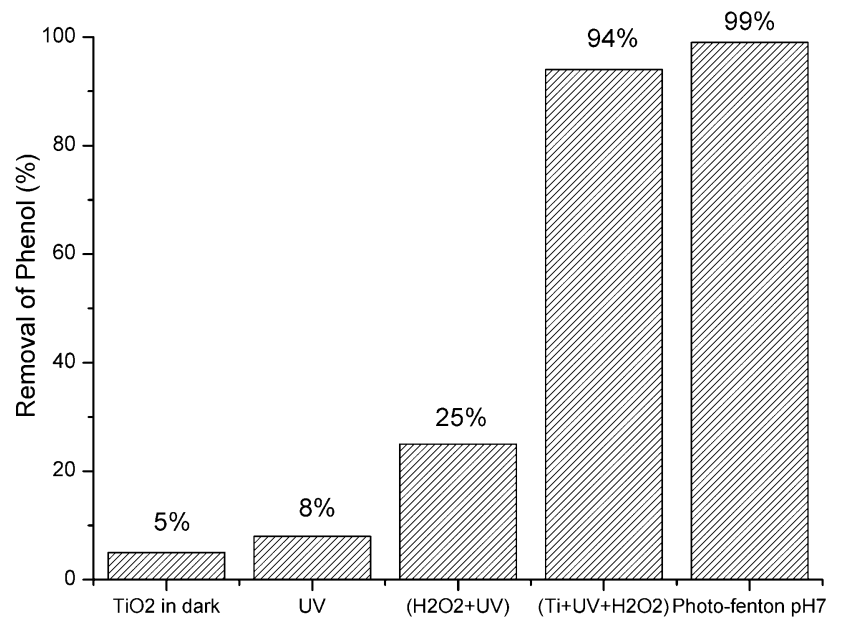

Fig. 7. Comparison of the different AOPs studied in this work, for degradation of phenol in seawater

\subsection{Water Produced from Oil (OPW)}

\subsubsection{Heterogeneous-Photocatalysis}

The UV-Vis spectra scan of the effluent before Heterogeneous-Photocatalysis is shown in Fig. 8. As is presented, the initial OPW profile has a principal band at 254 nm, which was attributed to the dissolved organic matter (Albrektien et al., 2012); the decrease in the profile intensity of this UV-Vis spectral was utilized to monitor the efficiency of AOP (Claro, 2013).

In the spectra scan of the effluent after heterogeneousphotocatalysis, the strong band below $300 \mathrm{~nm}$, corresponds to the remaining $\mathrm{H}_{2} \mathrm{O}_{2}$, which has a high absorption in this region. Therefore, this region was not considered for analysis. On the other hand, at pHs 3 and 7, the two photocatalytic process caused a greater character alteration in the region from 300 to $400 \mathrm{~nm}$ (indicated with a narrow black in the Fig. 8), indicating that the photocatalytic process was effective to remove the dissolved organic matter present in OPW at these pHs (Tambani, 2011).

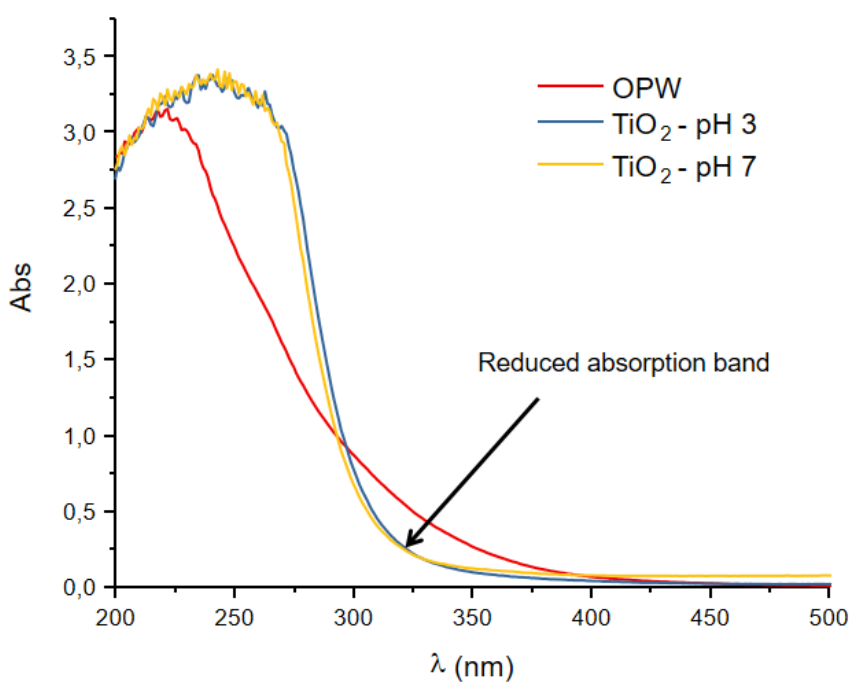

Fig. 8. UV-Vis scan profile of OPW after 3 hours of HeterogeneousPhotocatalysis over $\mathrm{TiO}_{2}$ plus $\mathrm{H}_{2} \mathrm{O}_{2}(0.3 \% \mathrm{v} / \mathrm{v})$, under UV irradiation (254nm).

In the next experiment, the same experiments described above were carried out (Heterogenous-Photocatalysis at $\mathrm{pH} 3$ and 7 for three hours of UV irradiation), but, this time with heating at $75^{\circ} \mathrm{C}$ and the results are shown in Fig. 9. In this Figure there was a greater alteration (of the peak related to organic matter located in intervals of 300-400 nm) when compared with the results obtained at room temperature (Fig. 8). This change of character is more notable for the photocatalysis at $\mathrm{pH}$ 7. It is known that the temperature is not a very relevant factor for the $\mathrm{UV} / \mathrm{H}_{2} \mathrm{O}_{2}$ system and for hydroxyl radical generation (Gonçalves, 2004), however, the improvement of the removal of dissolved organic matter is clear. In this sense, we can affirm that the temperature favored the kinetics of the reaction (by increasing the kinetic energy of molecules), resulting in a higher oxidation rate.

\subsubsection{Photo-Fenton}

The UV-Vis spectra scan of the effluent after PhotoFenton is shown in Figure 10. Similar to the analysis in heterogeneous-photocatalysis, the alteration of the initial OPW profile, which has a principal band at $254 \mathrm{~nm}$ attributed to the dissolved organic matter (Albrektien et al., 2012); served to monitor the efficiency of AOP (Claro, 2013).

In the spectra scan of the effluent after Photo-Fenton, the strong band below $275 \mathrm{~nm}$, corresponds to the remaining $\mathrm{H}_{2} \mathrm{O}_{2}$, which has a high absorption in this region. Therefore, this region was not considered for analysis. The Photo-Fenton carried out at $\mathrm{pH} 3$ and 7 led to alteration of the OPW profile above $275 \mathrm{~nm}$, indicating that the photocatalytic process was 
effective, the profile that corresponds to $\mathrm{pH} 7$ denoted a more demarked difference when compared to the initial profile of OPW above $275 \mathrm{~nm}$ (see the black arrows in Fig.10).

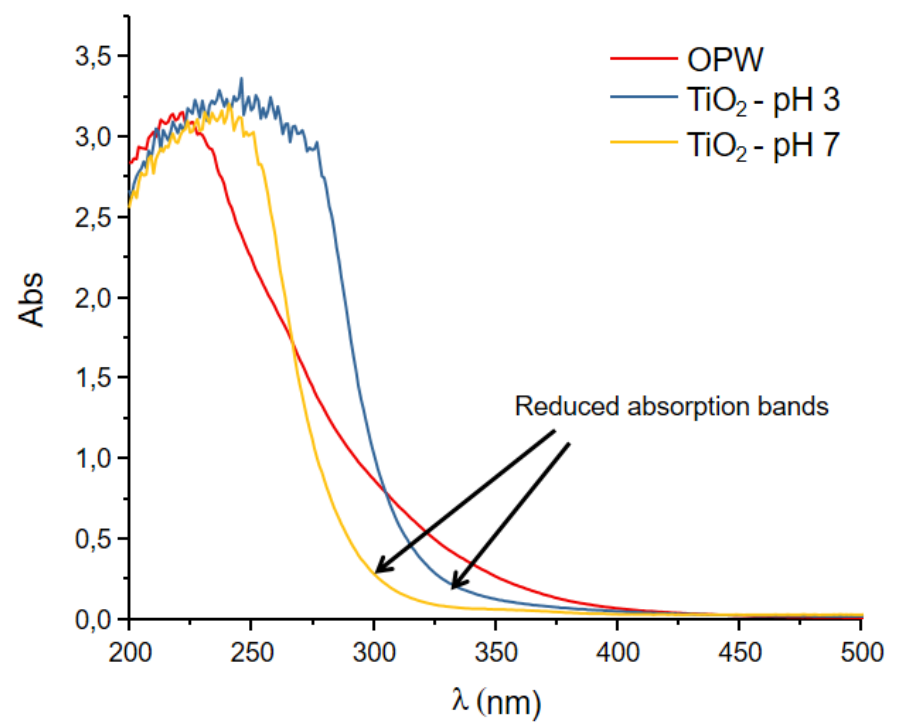

Fig. 9. UV-Vis scan profile of OPW after 3 hours of Heterogeneous-Photocatalysis over $\mathrm{TiO}_{2}$ plus $\mathrm{H}_{2} \mathrm{O}_{2}(0.3 \% \mathrm{v} / \mathrm{v})$, under UV irradiation $(254 \mathrm{~nm})$, and heating at $75^{\circ} \mathrm{C}$.

The same experiments described above (Photo-Fenton at $\mathrm{pH} 3$ and 7 for three hours under UV irradiation), were carried out but with heating at $75^{\circ} \mathrm{C}$ (Fig. 11). There was a greater change of character in the absorption band above $275 \mathrm{~nm}$, related to organic matter in OPW, when compared with the similar at room temperature (see Figs. 10,11 ).

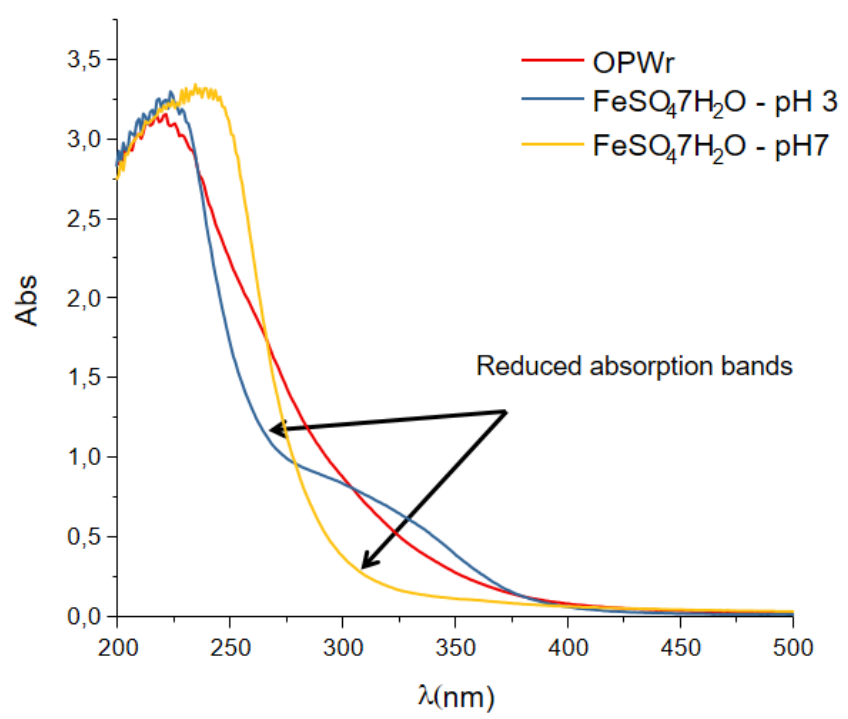

Fig. 10. UV-Vis scan profile of OPW after 3 hours under UV irradiation $(254 \mathrm{~nm})$, Photo-Fenton process with $\mathrm{FeSO}_{4} .7 \mathrm{H}_{2} \mathrm{O}$ plus $0.375 \mathrm{~mL} \mathrm{H}_{2} \mathrm{O}_{2}$.

This change was more marked for the photocatalysis at $\mathrm{pH}$ 7. As it is known, the temperature is not a very relevant factor for the $\mathrm{UV} / \mathrm{H}_{2} \mathrm{O}_{2}$ system and for the hydroxyl radical generation (Gonçalves, 2004). Nevertheless, the improvement of the removal of dissolved organic matter is clear. At this point, we can affirm that the temperature favored the kinetics of the reaction (by increasing the kinetic energy of organic molecules), resulting in a higher oxidation rate.

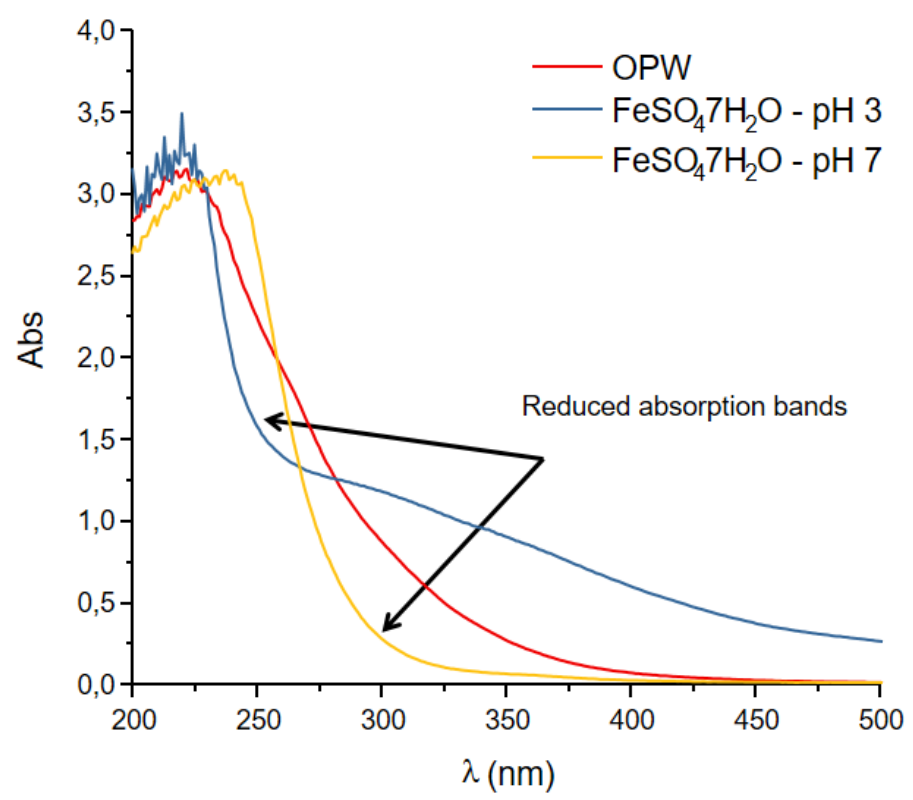

Fig. 11. UV-Vis scan profile of OPW after 3 hours under UV irradiation $(254 \mathrm{~nm})$, Photo-Fenton process with $\mathrm{FeSO}_{4} \cdot 7 \mathrm{H}_{2} \mathrm{O}$ plus $0.375 \mathrm{~mL} \mathrm{H}_{2} \mathrm{O}_{2}$ and heating at $75^{\circ} \mathrm{C}$.

\section{Conclusion}

The results of Photo-Fenton and HeterogeneousPhotocatalysis (both in the presence of $\mathrm{H}_{2} \mathrm{O}_{2}$ ) for the degradation of phenol in seawater, indicated that these processes are favored at low $\mathrm{pH}(<\mathrm{pH} 7)$, the kinetics of the processes were also favored. These processes were very favorable despite the high salt content in the seawater. The efficiency of the Photo-Fenton process reached $\approx 99 \%$ at $\mathrm{pH} 7$.

The Photo-Fenton process was more effective than Heterogeneous-Photocatalysis to treat the two types of effluents studied in this work. In the case of the effluent made of phenolic solution in seawater, the treatment did not generate any intermediates (detected by liquid chromatography) indicating the mineralization of phenol to $\mathrm{CO}_{2}$ and $\mathrm{H}_{2} \mathrm{O}$.

The results of OPW treatment by HeterogeneousPhotocatalysis and Photo-Fenton, demonstrated that the two photocatalytic processes were effective for the removal of dissolved organic matter in OPW, the best treatment was at $\mathrm{pH}$ 7. These processes were improved by heating at $75^{\circ} \mathrm{C}$.

In future trials, it is feasible to substitute the UV irradiation of lamps by sunlight, constituting an alternative with lower energy and sustainable consumption.

This study demonstrates that the two AOPs can be used in the oil industry, for OPW treatment and effluents (with high salinity) contaminated with phenol, to remove organic molecules in order to reduce their toxicity, and consequently provide better quality to the sedimentary environment. 


\section{Acknowledgment}

The authors thank to São Paulo Research Foundation (FAPESP) for the financial support (Grant No 2014/24940-5), the Brazilian National Council for Scientific Development

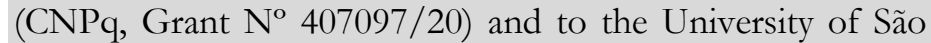
Paulo (USP, CEPEMA) for the analysis by High Performance Liquid Chromatography analysis (HPLC).

\section{References}

Albrektiene, R., Rimeika, M., Zalieckiene, E., Saulys, V., Zagorkis, A., 2012. Determination of Organic Matter by UV Absorption in Ground Water. Journal of Environmental Engineering and Landscape Management $20 \quad$ (2), $\quad$ 163-167. https://doi.org/10.3846/16486897.2012.674039

Ahmadun, F-R., Pendastech, A., Abdullah, L.C., Biak, D.R.A., Madaeni, S.S., Abidin, Z.Z., 2009. Review of technologies for oil and gas produced water treatment. Journal of Hazardous Materials 170, 530551. https://doi.org/10.1016/j.jhazmat.2009.05.044

APHA Method D 5530, 1989. Standard Methods for the Examination of Water and Wastewater, American Public Health Association (APHA), Washington.

Atkins, J., Jones, L., 2010. Chemical Principles. $5^{\text {th }}$ edition. New York: W.H. Freeman and Company.

Bakke, T., Klungsøyr, J., Sanni, S., 2013. Environmental impacts of Produced Water and Drilling Waste Discharges from the Norwegian Offshore Petroleum Industry. Marine Environmental Reasearch 92, 154-169. https://doi.org/10.1016/j.marenvres.2013.09.012

Carp, O., Huisman, C.L., Reller, A., 2004. Photoinduced reactivity of titanium dioxide. Progress in Solid State Chemistry, Bucareste 32(1-2), 33-177. http://dx.doi.org/10.1016/j.progsolidstchem.2004.08.001

Carvalho, P.C.A., 2016. Tratamento Combinado de água produzida de petróleo: filtração, adsorção e foto-fenton. $\mathrm{PhD}$. Thesis in Petroleum Engineering, Universidade Federal do Rio Grande do Norte, Brazil. https://repositorio.ufrn.br/jspui/handle/123456789/21946

Cheriyan, M., Rajagopalan, N., 1998. Membrane processing of oily streams. Wastewater treatment and waste reduction. Journal of Membrane Science 151 (1), 13-28. https://doi.org/10.1016/S0376-7388(98)00190-2

Claro, E.M.T., 2013. Potential of application of the Photocatalytic Process in Piracicaba River water. Master Thesis. Campinas State University.

EPA Method 604, 1984. Methods for organic chemical analysis of municipal and industrial wastewater. Environmental Protection Agency EPA. Part VIII, 40 CFR Part 136, Appendix A.

Gonçalves, A.C., 2004. Treatment of effluents containing free cyanide through the system $\mathrm{H}_{2} \mathrm{O}_{2}$. PhD Thesis, Pontifical Catholic University of Rio de Janeiro.

Ibhadon A.O., Fitzpatrick P., 2013. Heterogeneous Photocatalysis: Recent Advances and Applications. Catalysts 3 (1), 189-218. https://doi.org/10.3390/catal3010189

Jing, L., Chen, B., Zhang, B., Zheng, J., Liu, B., 2014. Naphthalene degradation in seawater by UV irradiation: The effects of fluence rate, salinity, temperature and initial concentration. Marine Pollution Bulletin 81(1), 149-156. https://doi.org/10.10.16/jmarpolbul.2014.02.003

Judd, S., Qiblawey, H., Al-Marri, M., Clarkin, C., Watson, S., Ahmed, A., Bach, S., 2014. The size and performance of offshore produced water oil-removal technologies for reinjection. Separation and Purification Technology 134, 241- 246. https://doi.org/10.1016/j.seppur.2014.07.037

Jenkins, R., Snyder, R.L., 1996. Introduction to X-ray Diffractometry, Wiley, New York, NY.

Kiwi, J., Lopez, A., Nadtochenko, V., 2000. Mechanism and Kinects of the OH-Radical Intervention during Fenton Oxidation in the Presence of a Significant Amount of Radical Scavenger (Cl-). Environmental science \& technology 34 (11), 2162-2168. http://dx.doi.org/10.1021/es991406i

Kuo, W.G., 1992. Decolorizing dye wastewater with Fenton's reagent. Water Research 26(7), 881-886. https://doi.org/10.1016/0043-1354(92)90192-7

Liu, B., Chen, B., Zhang, B.Y., Jing, L., Zhang, H., Lee, K. J., 2016. Photocatalytic Degradation of Polycyclic Aromatic Hydrocarbons in Offshore Produced Water: Effects of Water Matrix. Journal of Environmental Engineering 142(11), 1-7. https://ascelibrary.org/doi/10.1061/\%28ASCE\%29EE.19437870.0001135

Moraes, J.E.F., 2003. Photo-Fenton process application in the degradation of industrial effluents containing organic pollutants. $\mathrm{PhD}$ Thesis in Chemical Engineering, University of São Paulo, Brazil.

Neff, J.M., 2002. Bioacumulation in marine organisms effect of contaminants from oil well produced water, Elsevier Science, Duxbury.

Nogueira, R.F.P., Jardim, W.F., 1998. A fotocatálise heterogênea e sua aplicação ambiental. Química Nova 21(1). http://dx.doi.org/10.1590/S0100-40421998000100011

Ray, J.P., Engelhardt., 1992. Produced water: Technological / Environmental issues and solutions, Springer Science + Business Media, Pittsburgh.

Seftel, E.M., Puscasu, M.C., Mertens, M., Cool, P., Carja, G., 2014. Assemblies of nanoparticles of $\mathrm{CeO}_{2}-\mathrm{ZnTi}$-LDHs and their derived mixed oxides as novel photocatalytic systems for phenol degradation. Applied Catalysis B: Environmental 150- 151, $157-$ 166. https://doi.org/10.1016/j.apcatb.2013.12.019

Sun, X., Zhang, H., Yu, W.Q., Yang, P., Zhang, F., 2016. Preparation of pointline Bi2WO6@TiO2 nanowires composite photocatalysts with enhanced UV/visible-light- driven photocatalytic activity. Material Science in Semicondutor Processing, Harbin 45, 51-56. https://doi.org/10.1016/j.mssp.2016.01.015

Tambani, P.C., 2011. Estudo da degradação do fenol e sais intermediários pelo processo $\mathrm{UV} / \mathrm{H}_{2} \mathrm{O}_{2}$. Dissertação, Universidade de São Paulo, Escola Politécnica, Brazil.

Wang, C., Zhang, S., Zhang, Z., Zeng, M., Yuji, S., 2014 Optimization and interpretation of Fenton and UV/Fenton processes for degradation of syringyl lignin. Journal of Environmental Analytical Chemistry 1(2), 1-5. http://dx.doi.org/10.4172/JREAC.1000115

Wood, D.L., Tauc, J., 1972. Weak Absorption Tails in Amorphous Semiconductors. Physical Review B 5(8), 3144- 3151. https://doi.org/10.1103/PhysRevB.5.3144

Xu, D., Cheng, B., Cao, S., Yu, J., 2015. Enhanced photocatalytic activity and stability of Z-scheme $\mathrm{Ag}_{2} \mathrm{CrO}_{4}-\mathrm{GO}$ composite photocatalysts for organic pollutant degradation. Applied Catalysis B: Environmental 164, 380-388. https://doi.org/10.1016/j.apcatb.2014.09.051 
Zhu, C., Zhang, L., Jiang, B., Zheng, J., Hu, P., Li, S., Wu, M., Wu, W., 2016. Fabrication of Z-scheme $\mathrm{Ag}_{3} \mathrm{PO}_{4} / \mathrm{MoS}_{2}$ composites with enhanced photocatalytic activity and stability for organic pollutant degradation. Applied Surface Science 377, 99-108. https://doi.org/10.1016/j.apsusc.2016.03.143 